\title{
The Determination of Supplier of Raw Materials using Analytical Hierarchy Process Method (AHP)
}

\author{
Nasrun Baldah ${ }^{1}$, Desy Tri Inayah ${ }^{2}$, Dede Amar Udi IIma ${ }^{3}$, Ratih Andi K. ${ }^{4}$ \\ Department of Management, Universitas Pelita Bangsa-Bekasi, Indonesia ${ }^{1}$ \\ Department of PKK, Universitas Sarjanawiyata Tamansiswa-Yogyakarta, Indonesia ${ }^{2}$ \\ Faculty of Law, Universitas Muhammadiyah Yogyakarta-Yogyakarta, Indonesia ${ }^{3}$ \\ Department of Budget Planning, Universitas Pembangunan Nasional Veteran-Yogyakarta, Indonesia ${ }^{4}$ \\ nasrun.baldah@pelitabangsa.ac.id ${ }^{1}$,desytri@ustjogja.ac.id², dedeamarudiilma07@gmail.com³, \\ ratih_andi@upnyk.ac.id ${ }^{4}$
}

\begin{abstract}
This study aims to make a priority order of criteria in the selection of suppliers and determine which suppliers are selected. Data collection and sampling using questionnaires and purposive sampling. The data analysis method uses the Analytical Hierarchy Process to choose the best supplier as a priority based on criteria. The results showed that the quality criteria on preference, the criteria for delivery and price criteria, as second and third, respectively. Finally, based on the overall alternative weight value, supplier A has the highest value as the best supplier, followed by supplier B and C being the second and third positions.
\end{abstract}

Keywords: Analytical Hierarchy Process, Alternative Weight Values, Supplier Selection

\section{Introduction}

The currently established business competition requires companies to formulate business strategies and tactics carefully. The essence of competition lies in how companies can implement the process of making the latest products and services, affordable and fast prices. Customers certainly expect goods with high quality but at low cost, both from companies and individuals. Of course, this is very decisive in the selection of suppliers to optimize costs. [1].

Purchasing decisions become more important with the consequence of increasing the purchasing function [2]. This paper is described as relevant previous research to determine suppliers, along with multiple-criteria decision-making methods. Analytical Hierarchy Process is used to select suppliers through six, produce a systematic approach to criteria weights, and is used to assess performance suppliers [3]. Analytical hierarchy process approaches to assist managers in dividing complex decision- making problems into simpler hierarchies. Sensitivity analysis allows for understanding the effects of changes in essential criteria on supplier ratings. It helps make decisions to check the stability of the whole process [4].

The scope of this research is limited to the manufacturing industry in West Java-Indonesia; managers are presented with complex problems. So, it takes a lot of time to create the right decision, and the elements need to consider in a company is financial sustainability. Analysis results showed decreased inefficiency due to the delay in raw materials and quality problem materials (from supplier). New findings in this study are the proposed Analytic Hierarchy Process (AHP) to facilitate and assist practitioners in complex problems. 


\section{Literature Review}

\subsection{AHP (Analytical Hierarchy Process)}

The AHP principle relies on experts' judgment of pairwise comparisons to get a scale of priorities in measuring the various elements considered. [5]. It is a procedure for decision making to set priorities in many criteria [6]. And they are specifically designed to match the decisions taken by experts [7]. As decisions often affect several people, AHP standards have been adapted to apply in group decisions [8]. There are two steps to using AHP, firstly, distributing questionnaires to experts for the criteria that they consider relevant in selecting suppliers. Secondly, Discussing the proposed criteria to clarify the meaning, operation, and determine the final criteria [9].

The strength of AHP lies in the ability to arrange the number of experts and the problem of many attributes in a hierarchical manner. Furthermore, it analyzed at each level of the hierarchy, combining the results of the analysis. The hierarchy level describes the system from the lowest level (alternative), intermediate (sub-criteria) to the highest level (general) [3].

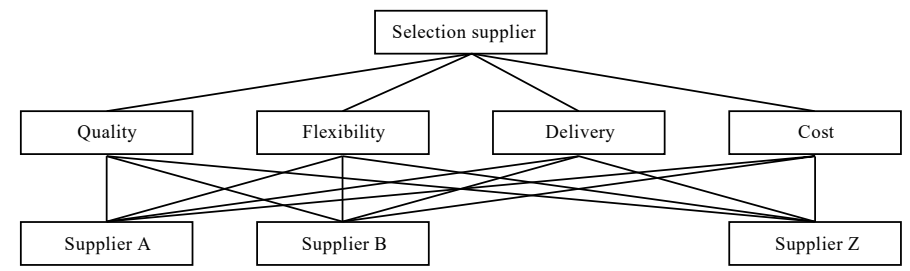

Fig.1. Three levels of hierarchy for selecting suppliers

Figure 1 shows that the use of ratio to compare with all pairs and supplier criteria [10]. AHP can utilize qualitative and quantitative factors to form a hierarchical structure in the decision- making process; then it can help decision-makers to choose the best option based on the selection criteria presented in the model [11].

\subsection{Supplier Selection}

Companies need equipment, services, and optimal raw materials, which play a vital role in the purchasing department in selecting suppliers [4]. Suppliers play an important role in supply chain management, which involves evaluating supplier selection issues as well as many other matters that should be considered by the organization [12]. Sustainable supplier selection faces many uncertainties [13], In literature, many approaches in selecting criteria and performance appraisal were used in the selection of suppliers.[14]. Supplier criteria and performance are used as a basis for making decisions on supplier selection. [15]. Meanwhile, new criteria for decision making are proposed by [6].

The criteria for developing partnerships with members of an organization's supply chain are usually driven by quality, cost efficiency, delivery, the accuracy of quantity, information, and services [3], [6], [16]. Each supplier selection is different. The firms have a multiple determination of methods based on their product, expectations, criteria, and the industry [2]. 


\section{Research Methodology}

\subsection{Research Design}

Figure 2 shows the problem identification process begins by determining the five supplier criteria consisting of price, service, delivery, and quantity [3], [6], [16]. Then build an overall hierarchical structure. Respondents in this study were quality managers, production managers, engineering managers, purchasing managers, and warehouse chiefs. AHP method is used to analyze each parameter in the study. Finally, the criterion analysis (primary and alternative) are used to determine the best supplier.

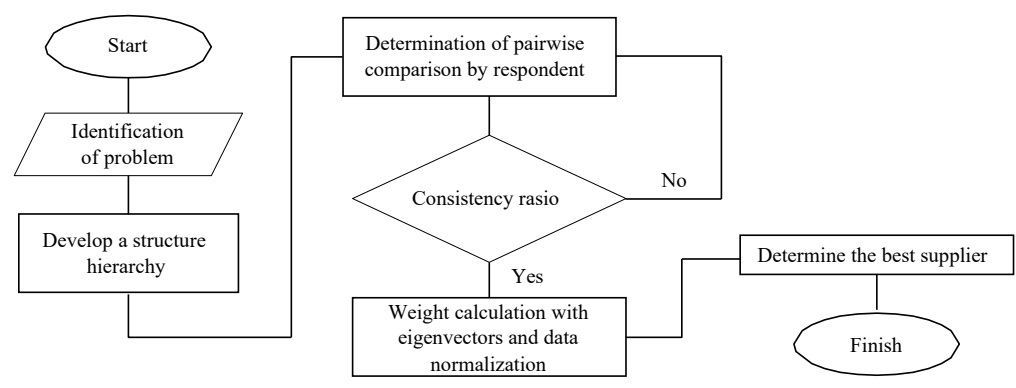

Fig.2. Research Flowchart

\subsection{Six Steps Procedure}

There are six steps for AHP to determining the best supplier in Figure 3 as follows.

Step 1. Determine the problem and the solution, the overall criteria for evaluating the performance to selected supplier.

Step 2. Develops the overall hierarchical structure, starting from the objectives to be achieved, criteria, and alternatives, the results of research on the AHP structure hierarchy are presented in Figure. 3.

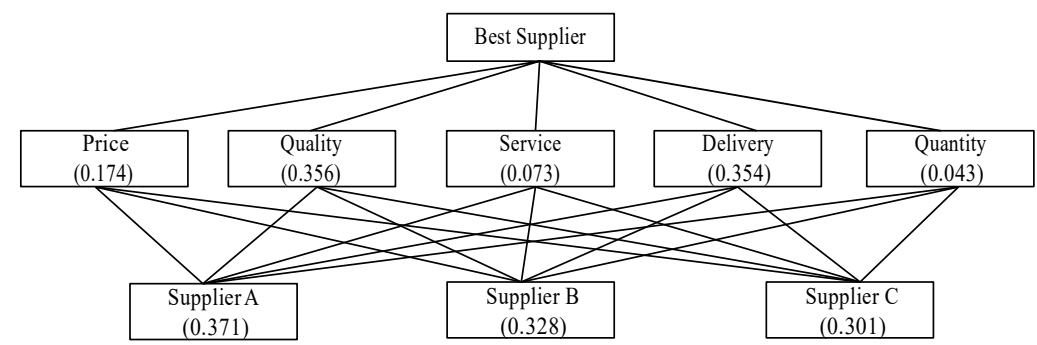

Fig.3. The hierarchy of determining the best supplier

Step 3. In this step, create a pairwise comparison matrix of criteria \& alternatives. Respondents subjectively assess interests between elements using a scale 1, 3, 5, 7, and 9. Where 1 refers to "equally important," 3 donates "moderately important," 5 equals "strongly more important," 7 represents "very more important," and 9 donate "extremely important," 2, 4, 6, 8 "intermediate values between the two adjacent judgment”[17].

Step 4. Eigenvector value calculation and normalization of criteria \& alternatives 
Step 5. For consistency ratio of respondents', by determining the maximum eigenvalue $\left(\lambda_{\max }\right)$ to calculate the consistency index $(\mathrm{CI})=\left(\lambda_{\max }-\mathrm{n}\right) /(\mathrm{n}-1)$. We can declare the consistency ratio through CI / RI, where RI can be specified in Table 1 by [18].

Table 1. Avarage of random consistency (RI)

\begin{tabular}{ccccccccccc}
\hline Size of Matrix & 1 & 2 & 3 & 4 & 5 & 6 & 7 & 8 & 9 & 10 \\
\hline Random Consistency & 0 & 0 & 0.58 & 0.9 & 1.12 & 1.24 & 1.32 & 1.41 & 1.45 & 1.49 \\
\hline
\end{tabular}

Step 6. Calculate of supplier ratings based on Eigenvector by normalizing the weight values of several alternatives.

\section{Discussion}

\subsection{Weight Priority of Criteria}

The selecting suppliers consist of five criteria that are quality, delivery, price, service, and quantity. Figure 4 shows the weight criteria (quality, delivery, price, service, and quantity) after normalizing them.

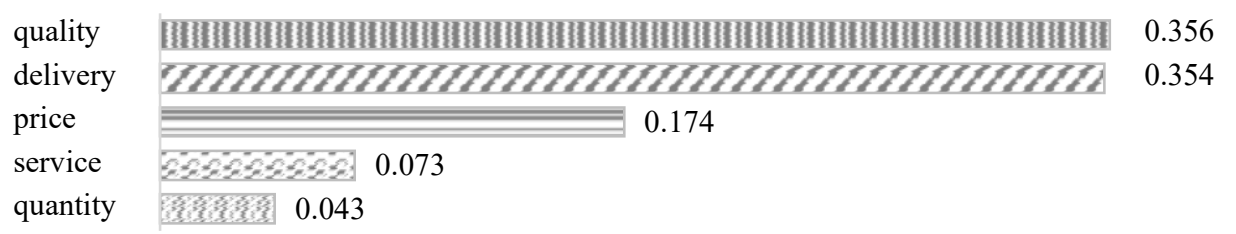

Fig.4. Weight priority of criteria

The highest weight is quality. Quality is the main consideration in determining suppliers and following company policy. The process of quality is a fundamental aspect; it starts from raw materials, internal processes of the company until the operation of shipping by installing goods to the price with specified quality. The results showed that delivery was the second priority after quality. It is not in line with research conducted by [3]. This difference tends to be caused by problems that occur in the company related to product quality from suppliers. The supplier selection process indicated to be reviewed, especially regarding the personnel responsible therein.

\subsection{Selection Suppliers}

The alternative weights of each criterion are determined according to Table 2. 
Table 2. Global Priority

\begin{tabular}{ccccc}
\hline Goal & Criteria & Weight & Alternative & Weight \\
\hline Best supplier & Price & 0.174 & Supplier A & 0.427 \\
& & Supplier B & 0.320 \\
& & Supplier C & 0.253 \\
& & & Supplier A & 0.361 \\
& & 0.356 & Supplier B & 0.378 \\
& & & Supplier C & 0.261 \\
& \multirow{2}{*}{ Service } & 0.073 & Supplier A & 0.271 \\
& & Supplier B & 0.298 \\
& & & Supplier C & 0.431 \\
& \multirow{2}{*}{ Delivery } & \multirow{2}{*}{0.354} & Supplier A & 0.480 \\
& & Supplier B & 0.213 \\
& & Supplier C & 0.307 \\
& & & Supplier A & 0.211 \\
& \multirow{2}{*}{0.043} & Supplier B & 0.310 \\
& & Supplier C & 0.479 \\
\hline
\end{tabular}

Table 3 presents the value of the weight calculation between criteria and alternatives, then the eigenvector value is normalized, the results are shown in Figure 5.

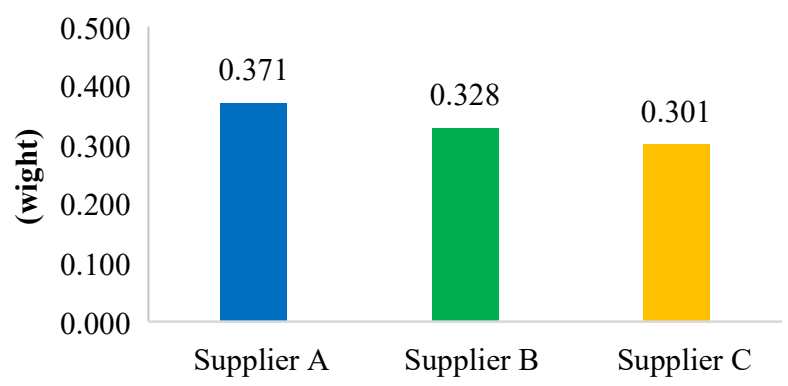

Fig.5. Determine the best supplier

Figure 5 shows that overall supplier A with a weight value of 0.371 is the priority to be chosen as a supplier. The second priority is supplier B, with a weight value of 0.328 . while the last priority is supplier $\mathrm{C}$ with a weight value of 0.301 . The selection of suppliers in the company emphasizes it tends to personal relationships, whereas in the current development of the business demands improvement to be able to compete for the sustainability of the organization. In this research, AHP is one of the solutions to determine supplier selection based on several main criteria that have been set by [3].

\subsection{Consistency Ratio}

The consistency ratio is used to determine the level of consistency in pairwise comparisons between criteria and alternatives. If the result of the calculation is consistent, it can proceed to the next stage. In contrast, the results of the analysis are inconsistent. It necessity be repeated starting from the beginning. A contradictory statement by the respondent can cause this evidence. The study of the consistency ratio is shown in Table 4. 
Table 4. Consistency ratio (CR) of the respondent

\begin{tabular}{lll}
\hline Pairwise comparison & CR & Judgment \\
\hline Between criteria & 0.042 & consistent \\
Between alternatives on price & 0.031 & consistent \\
Between alternatives on quality & 0.004 & consistent \\
Between alternatives on service & 0.001 & consistent \\
Between alternatives on delivery & 0.017 & consistent \\
Between alternatives on quantity & 0.018 & consistent \\
\hline
\end{tabular}

Table 4 shows the consistency ratio $(\mathrm{CR})<0.1$. it can conclude that all respondents' statements in the pairwise comparison are consistent. These results are in line with previous studies conducted by [18]. It means that the calculation results can be continued to the next step.

\section{Conclusion}

The main criteria in supplier selection are quality. In terms of alternative supplier selection, supplier "A" was chosen as the priority. AHP is one method that can be used to determine the selection of the best suppliers for the company's business partners. Finally, In the next stage, the same method will be used in determining other policies and business strategies of the company both short and long term and can be combined with other methods such as TOPSIS and others.

\section{References}

[1] Shendryk, D., Bychko, D., Parfenenko, Y., Boiko, O., Ivashova, N.: Information system for selection the optimal goods supplier. Procedia Computer Science. vol. 124, pp. 57-64 (2019)

[2] Taherdoost, H., Brard, A.: Analyzing the Process of Supplier Selection Criteria and Methods. Prodecia Manufacturing. vol. 32, pp. 1024-1034 (2019)

[3] Liu, F.H.F and Hai, H. L.: The voting analytic hierarchy process method for selecting supplier. International Journal of Production Economics. vol. 97, no. 3, pp. 308-317 (2005)

[4] Dweiri, F., Kumar, S., Khan, S. A., and Jain, V.: Designing an integrated AHP based decision support system for supplier selection in automotive industry. Expert Systems with Applications. vol. 62, pp. 273-283 (2016)

[5] Malik, M.M., Abdallah, S., Hussain, M.: Assessing supplier environmental performance: Applying Analytical Hierarchical Process in the United Arab Emirates healthcare chain. Renewable and Sustainable Energy Reviews. vol. 55, pp. 1313-1321 (2016)

[6] Ho, W., Xu, X., and Dey, P. K.: Multi-criteria decision making approaches for supplier evaluation and selection: A literature review. European Journal of Operational Research. vol. 202, no. 1, pp. 333-343 (2010)

[7] Bernasconi, M., Choirat, C., Seri, R.: The Analytic Hierarchy Process and the Theory of Measurement. Management Science. vol. 56, no. 4, pp. 699-711 (2010)

[8] Ishizaka, A., Labib, A.: Review of the main developments in the analytic hierarchy process. Expert System Applicaation. vol. 38, no. 11, pp. 14336-14345 (2011)

[9] Yahya, S., and Kingsman, B.: Vendor rating for an entrepreneur development programme: a case 
study using the analytic hierarchy process method. Journal of the Operational Research Society. vol. 50, no. 9, pp. 916-930 (1999)

[10] Levary, R.R.: Using the analytic hierarchy process to rank foreign suppliers based on supply risks. Computers \& Industrial Engineering. vol. 55, no. 2, pp. 535-542 (2008)

[11] Chan, H. K., Sun, X., Chung, S. H.: When should fuzzy analytic hierarchy process be used instead of analytic hierarchy process. Decision Support Systems. vol. 125, pp. 113-114 (2019)

[12] Konys, A.: Methods supporting supplier selection processes - Knowledge-based approach. Procedia Computer Science. vol. 159, pp. 1629-1641 (2019)

[13] Hendiani, S., Mahmoudi, A., Liao, H.: A multi-stage multi-criteria hierarchical decision-making approach for sustainable supplier selection. Applied Soft Computing Journal, vol. 94, pp. 106456 (2020)

[14] Santos, L., Osiro, L., Lima, R.: A model based on 2-tuple fuzzy linguistic representation and Analytic Hierarchy Process for supplier segmentation using qualitative and quantitative criteria. Expert System Applications. vol. 79, pp. 1339-1351 (2017)

[15] Liao C.N., Kao, H.P.: Supplier selection model using Taguchi loss function, analytical hierarchy process and multi-choice goal programming. Computers Industrial Engineering. vol. 58, no. 4, pp. 571-577 (2010)

[16] Kahraman, C., Cebeci, U., Ulukan, Z.: Multi-criteria supplier selection using fuzzy AHP. Logistics Information Management. vol.16., no. 6, pp. 382-394 (2003)

[17] Saaty, T. L.: Decision making with the analytic hierarchy process. International Journal Service Sciences. vol. 1, no.1, pp. 83-98 (2008)

[18] Kocaoglu, B., Gulsun, B., Tanyas, M.: A SCOR based approach for measuring a benchmarkable supply chain performance. Journal of Inteligent Manufacturing. vol. 24, no.1, pp. 113-132 (2013) 